\title{
Effects of Insulin on Plasma Renin Activity, Plasma Atrial Natriuretic Peptide and Body Fluid Volume in Diabetes Mellitus
}

\author{
Tetsuya Nakamura, M.D., Shuichi Ichikawa, M.D.,* \\ Tetsuo Sakamaki, M.D., Futao Aizawa, M.D., \\ Toshiaki Kurashina, M.D., Kunio Sato, M.D., \\ Masao Fujie, M.D., and Kazuhiko Murata, M.D.
}

\section{SUMmary}

The effects of insulin treatment on plasma renin activity (PRA), plasma atrial natriuretic peptide (ANP) and body fluid volume were studied in 16 hospitalized patients with insulin-independent diabetes mellitus. Parameters were recorded for 2 days during treatment by diet alone and for 3 weeks after starting insulin. Blood samples were obtained weekly from 9 patients for the measurement of fasting plasma glucose, hematocrit, PRA and plasma ANP. A 24-hr urine sample was collected to determine the urinary excretion of glucose and sodium. In a separate group of 7 patients, plasma volume and extracellular fluid volume were determined by the Evans blue and sodium thiocyanate dilution tests, respectively.

In the group of 9 diabetic patients, significant $(\mathrm{p}<0.05)$ reductions in fasting plasma glucose, hematocrit and the urinary excretion of sodium and glucose were seen with insulin treatment. PRA fell significantly $(\mathrm{p}<$ 0.05 ) from $5.2 \pm 1.2 \mathrm{ng} / \mathrm{ml} / \mathrm{hr}$ (mean $\pm \mathrm{SEM}$ ) on the control days to $2.3 \pm$ 0.5 on the 21 st day after starting treatment. Plasma levels of ANP averaged $35 \pm 5 \mathrm{pg} / \mathrm{ml}$ on the control days and these did not change significantly. In the other group of 7 patients, both plasma volume and extracellular fluid volume increased significantly $(\mathrm{p}<0.05)$ with insulin treatment. A sodium-retaining effect of insulin and a decrease in osmotic diuresis may have increased the body fluid volume and caused the fall in PRA. Thus, a vasodilatory action of insulin may assist in compensation for the increase in body fluid volume, preventing a rise in plasma ANP levels.

\section{Additional Indexing Words:}

Atrial natriurctic peptide Renin Aldosterone Insulin

From the Second Department of Internal Medicine, Gunma University School of Medicine, Maebashi, Japan.

* Cardiovascular Hospital of Central Japan, Shimohakoda, Hokkitsumura, Gunma, Japan.

Address for correspondence: Tetsuya Nakamura, M.D., Department of Physiology, Eastern Virginia Medical School, Post Office Box 1980 Norfolk, VA 23501, U.S.A.

Received for publication August 7, 1989.

Accepted Fcbruary 13, 1990. 
Diabetes mellitus Plasma volume Extracellular fluid volume

DLASMA renin activity (PRA) has been reported as either elevated ${ }^{1)}$ or nor$1 \mathrm{mal}^{2), 3}$ in uncomplicated, long-standing diabetes mellitus. Dehydrated adult patients with diabetic ketoacidosis develop an osmotic diuresis with salt and water wasting, that leads to severe volume depletion and a marked rise in both PRA and the plasma aldosterone concentration." With subsequent fluid repletion and improved diabetic control, both PRA and the plasma aldosterone level fall rapidly. By contrast, low PRA has been reported in patients with long-term diabetes mellitus complicated by hypertension and nephropathy, ${ }^{5)}$ or orthostatic hypotension and peripheral neuropathy. ${ }^{6}$ )

Atrial natriuretic peptide (ANP) is a hormone released by atrial myocytes in response to acute and chronic volume expansion." $\mathrm{We}^{8)}$ and others $^{9 /}$ have reported that plasma ANP levels are closely correlated with atrial pressure. ANP release causes a marked stimulation of renal sodium excretion and has an inhibitory effect on renin secretion ${ }^{10)}$ and aldosterone release. ${ }^{11}$ These effects produce a significant negative correlation between the plasma ANP and PRA values. ${ }^{12), 13)}$ In the present study, we measured PRA, plasma ANP levels and body fluid volumes in patients with uncomplicated diabetes during a period of insulin therapy (1) to clarify the relationship between the renin-angiotcnsin-aldosterone system and ANP, and (2) to evaluate the role of these hormone systems in volume homeostasis in diabetes.

\section{Methods}

Sixteen patients with insulin-independent diabetes mellitus who provided informed consent were studied. The known duration of diabetes ranged from 1 to 108 months, averaging $29 \pm 13$ months (mean \pm SEM). Three of the patients had newly-diagnosed diabetes and all patients were hospitalized during the study. Before admission, 8 patients had been controlled with diet, 6 with diet and oral hypoglycemic agents, and 2 with diet and insulin. However, in every case the therapy did not adequately control hyperglycemia. Two patients had evidence of retinopathy with microaneurysms but none had proteinuria, impairment of lower limb reflexes or sensation, or clinical evidence of renal failure (serum creatinine $>1.4 \mathrm{mg} / \mathrm{dl}$ ). There was also no evidence of hypertension, congestive heart failure, angina, arrhythmias or edema; physical examination, chest $\mathrm{x}$ ray and electrocardiogram were normal in all cases. Since a large amount of blood would need to be withdrawn to perform all measurements in one group of patients, 9 patients participated in the hormonal study and 7 in the determination of body fluid volume. Both groups 
were matched for age and sex.

\section{General protocol:}

After admission, oral hypoglycemic agents and insulin were discontinued. All patients were maintained on a diet of $1,200-1,800 \mathrm{kcal}$ daily with a constant sodium content $(120 \mathrm{mEq} /$ day $)$. Hyperglycemia and glycosuria were sustained in all cases but none had thirst, polydypsia or ketonuria. The studies were started at least 7 days after admission when the sodium balance was in equilibrium. Investigations covered 2 consecutive days during treatment with diet alone and 21 days after starting insulin administration. Porcine monocomponent insulin was given subcutaneously once or twice a day, the dose being determined according to the fasting plasma glucose level. Insulin was the only medication administered during the study period.

\section{Study 1. Hormonal study:}

Hormonal changes were studied in 9 patients. The subjects included 5 males and 4 females ranging in age from 34 to 67 years $(43 \pm 6$ years, mean \pm SEM). Subjects rested supine overnight before data collection; the blood pressure was measured with a sphygmomanometer and samples of venous blood were withdrawn at 7 a.m., just before rising. Blood was taken on 2 consecutive days during the control period and weekly after starting insulin administration to determine the plasma ANP, PRA, aldosterone and cortisol levels. Fasting plasma glucose, hematocrit, serum total protein, serum electrolytes and serum osmolality were also measured. Twenty-four hour urine collections were taken on the control days and on days 3, 7, 10, 14 and 21 for determination of the urinary excretion of electrolytes and glucose.

\section{Study 2. Determination of body fluid volume:}

Changes in body fluid volume were studied in a second group of 7 patients (3 males and 4 females), ranging in age from 35 to 74 years $(57 \pm$ 6 ycars). Blood samples for determination of fasting plasma glucose, hematocrit and PRA were obtained weekly, as described for the hormonal study. Both before and 21 days after starting insulin administration, plasma volume and extracellular fluid volume were respectively determined by the Evans blue (Daiichi Kagaku, Tokyo, Japan) ${ }^{14)}$ and sodium thiocyanate (NaSGN) (Daiichi Kagaku) ${ }^{15)}$ dilution tests. At 8 a.m., after resting supine for 1 hour in the fasting state, each patient voided and was given an intravenous injection of $3 \mathrm{ml}$ of $0.5 \%$ Evans blue and $20 \mathrm{ml}$ of $5 \%$ NaSCN. Blood samples were withdrawn into heparinized tubes without the aid of a tourniquet before the injection of the test substances, as well as 15 and 60 min after. Plasma was 
separated by centrifugation $(3,000 \mathrm{rpm}, 15 \mathrm{~min})$. Urine collection was performed for 1 hour after the injection. The optical density of Evans blue in plasma (obtained before and $15 \mathrm{~min}$ after the injection) was measured using a spectrophotometer (JASCO UVIDEC-320, Japan Spectroscopic, Tokyo, Japan) at $620 \mathrm{~nm}$. Plasma volume was calculated using the equation:

$$
\frac{\text { amount of Evans blue injected }(\mathrm{mg})}{\text { plasma concentration of Evans blue }(\mathrm{mg} / \mathrm{ml})}=\text { plasma volume }(\mathrm{ml})
$$

The NaSCN concentration in the collected urine and in deprotenized plasma obtained before and $60 \mathrm{~min}$ after the injection was measured according to the method of Bowler. ${ }^{16}$ ) Then the extracellular fluid volume was calculated with the equation:

$$
\frac{\mathrm{NaSCN} \text { injected }(\mathrm{mg})-\mathrm{NaSCN} \text { excreted }(\mathrm{mg})}{\text { plasma concentration of NaSCN }(\mathrm{mg} / \mathrm{ml})}=\begin{aligned}
& \text { extracellular fluid } \\
& \text { volume }(\mathrm{ml})
\end{aligned}
$$

\section{Analytical procedures:}

PRA and the plasma concentrations of aldosterone and cortisol were measured by radioimmunoassay, using methods reported previously. ${ }^{17}$ ) For the determination of immunoreactive ANP, 1-ml plasma aliquots were extracted on Sep-PAK Cl8 cartridges (Water Associates, Milford, Massachusetts, USA) before performing radioimmunoassay by a method described prcviously. ${ }^{18)}$ Synthetic $\alpha$-human atrial natriuretic peptide ( $\alpha$-hANP) was purchased from Peninsula Laboratories (Belmont, CA, USA). Labelled ${ }^{125} \mathrm{I}-\alpha-$ hANP and antibody against $\alpha$-hANP were kindly provided by Mitsubishi Yuka Laboratories of Medical Science. The efficacy of the extraction procedure was estimated by recovery of synthetic $\alpha$-hANP added to plasma. When $50-500 \mathrm{pg} / \mathrm{ml}$ of synthetic $\alpha$-hANP was added, plasma recovery was $81 \pm 2 \%$ (mean $\pm \mathrm{SEM}, \mathrm{n}=12$ ) after the extraction and radioimmunoassay procedures. The intra- and interassay coefficients of variation were 7.0 and $9.1 \%(n=10)$, respectively.

Plasma and urine glucose levels were measured by the glucose-oxidase method (New Glucoroder, Analytical Instruments, Tokyo, Japan). Serum and urine levels of sodium and potassium was measured by flame photometry (HITACHI 750 Flame Photometer, Hitachi, Tokyo, Japan) and serum total protein by Biuret methods (HITACHI 736-60E Automatic Analyzer, Hitachi, Tokyo, Japan). Serum osmolality was determined by freezing point depression osmometry (Digital Micro-osmometer, Vogel, West Germany). 
Statistical analysis:

The data for each experimental day after starting treatment were compared with the control data from before treatment by a Studentized range test preceded by two-way analysis of variance. In study 1 , control data used were the averages of 2 determinations. Plasma volume and extracellular fluid volume on day 21 were compared with the control period by Student's t-test for paired observations. Values are reported as the mean \pm SEM. A p value of less than 0.05 was considered significant.

\section{Results}

Study 1:

In the hormonal study group, the dose of insulin ranged from 8 to 22 I.U./day (16 \pm 2 I.U./day) on the final day of the study. Data concerning fasting plasma glucose and urinary excretion of glucose are shown in Fig. 1.

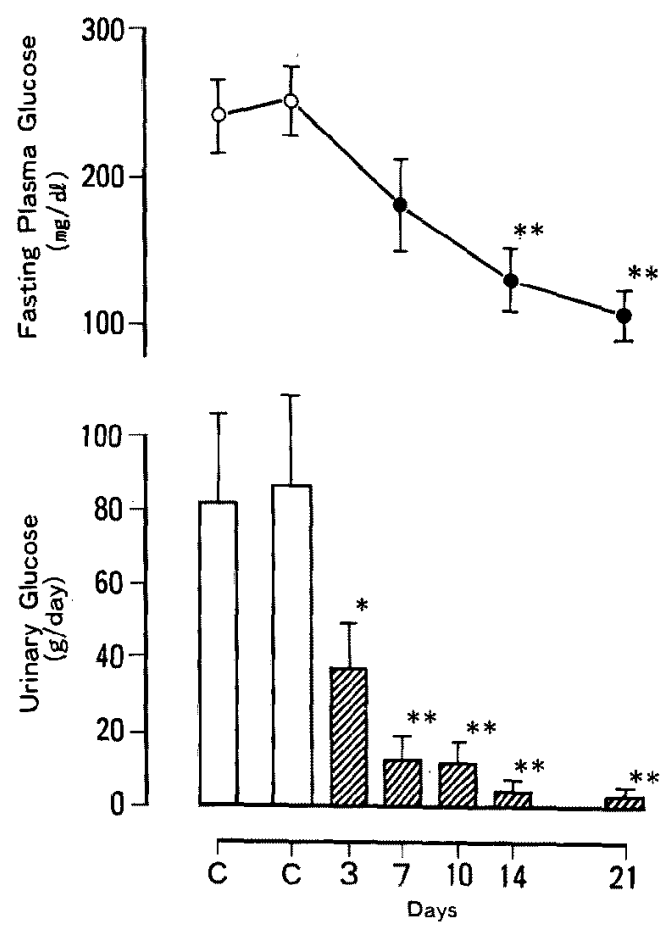

Fig. 1. Changes in fasting plasma glucose levels and daily urinary excretion of glucose (mean \pm SEM). Open circles and open bars show data before insulin treatment: Closed circles and shaded bars show data after starting insulin. $\mathrm{G}$ indicates the control days. Data from each day after starting treatment are compared with the mean of two determinations on the control days. * $\mathrm{p}<0.05, * * \mathrm{p}<0.01$. 
The mean control period level of fasting plasma glucose was $237 \pm 23 \mathrm{mg} / \mathrm{dl}$; it fell to $107 \pm 17 \mathrm{mg} / \mathrm{dl}$ on the 21 st day after starting insulin. Urinary excretion of glucose also fell markedly from $84 \pm 24 \mathrm{~g} /$ day during the control period to $3 \pm 2 \mathrm{~g} /$ day on day 21 .

The urinary excretion of sodium and potassium during the study period is shown in Fig. 2. The average urinary sodium excretion during the control period was $94 \pm 9 \mathrm{mEq} /$ day. This decreased markedly $(\mathrm{p}<0.05)$ after starting insulin, reaching its lowest level on day $3(51 \pm 7 \mathrm{mEq} /$ day), but it returned to the control level over the remainder of the study. Potassium excretion averaged $49 \pm 4 \mathrm{mEq} /$ day during the control period; it also decreased significantly on day $3(32 \pm 3 \mathrm{mEq} /$ day, $\mathrm{p}<0.05)$.

Table I summarizes results regarding the hematocrit, serum total protein, serum electrolytes, serum osmolality, blood pressure and plasma concentrations of cortisol and aldosterone. Both hematocrit and serum total protein
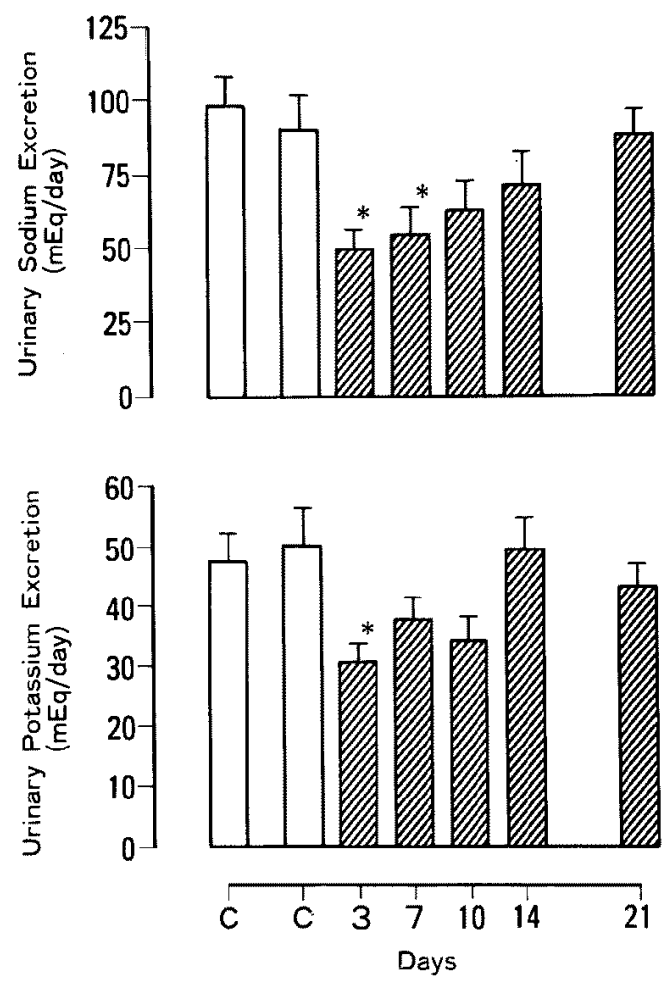

Fig. 2. Changes in daily urinary excretion of sodium and potassium (mean $\pm S E M)$. Open and shaded bars represent data before and after starting insulin, respectively. Cindicates the control days before treatment. Data from each day after starting treatment are compared with the mean of two determinations on control days. $* p<0.05$. 
Table I. Hematocrit, Serum Total Protein, Serum Electrolytes, Serum Osmolality, Blood Pressure and Plasma Levels of Cortisol and Aldosterone in the Hormonal Study (Study $1, n=9$ patients)

\begin{tabular}{|c|c|c|c|c|c|}
\hline & \multirow{2}{*}{\multicolumn{2}{|c|}{ Control days }} & \multicolumn{3}{|c|}{ Days after starting insulin } \\
\hline & & & 7 & 14 & 21 \\
\hline Hematocrit $(\%)$ & $42.5 \pm 0.9$ & $42.7 \pm 0.9$ & $41.1 \pm 1.2$ & $38.5 \pm 1.5^{* *}$ & $40.3 \pm 1.0^{*}$ \\
\hline $\begin{array}{l}\text { Serum total protein } \\
(\mathrm{g} / \mathrm{dl})\end{array}$ & $6.9 \pm 0.2$ & $6.9 \pm 0.1$ & $6.5 \pm 0.2^{* *}$ & $6.4 \pm 0.2^{* *}$ & $6.6 \pm 0.2^{* *}$ \\
\hline Serum sodium $(\mathrm{mEq} / \mathrm{l})$ & $140.6 \pm 0.9$ & $139.9 \pm 0.8$ & $143.0 \pm 1.1$ & $143.7 \pm 1.2^{*}$ & $143.7 \pm 1.4^{*}$ \\
\hline $\begin{array}{l}\text { Serum potassium } \\
(\mathrm{mEq} / \mathrm{l})\end{array}$ & $4.2 \pm 0.1$ & $4.3 \pm 0.2$ & $4.3 \pm 0.1$ & $4.3 \pm 0.1$ & $4.2 \pm 0.1$ \\
\hline $\begin{array}{l}\text { Serum osmolality } \\
\text { (mosmol } / \mathrm{kg})\end{array}$ & $290 \pm 4$ & $290 \pm 4$ & $291 \pm 3$ & $292 \pm 3$ & $289 \pm 4$ \\
\hline $\begin{array}{l}\text { Systolic blood pressure } \\
(\mathrm{mmHg})\end{array}$ & $112 \pm 7$ & $108 \pm 5$ & $106 \pm 6$ & $106 \pm 6$ & $101 \pm 5$ \\
\hline $\begin{array}{l}\text { Diastolic blood pres- } \\
\text { sure (mmHg) }\end{array}$ & $61 \pm 4$ & $61 \pm 3$ & $58 \pm 3$ & $61 \pm 5$ & $58 \pm 5$ \\
\hline Plasma cortisol ( $\mu \mathrm{g} / \mathrm{dl})$ & $14.3 \pm 1.9$ & $17.5 \pm 2.3$ & $14.4 \pm 2.7$ & $13.2 \pm 1.8$ & $11.4 \pm 1.9$ \\
\hline $\begin{array}{l}\text { Plasma aldosterone } \\
(\mathrm{pg} / \mathrm{ml})\end{array}$ & $129 \pm 19$ & $127 \pm 25$ & $106 \pm 11$ & $102 \pm 8$ & $94 \pm 10$ \\
\hline
\end{tabular}

Values are mean $\pm S E M$. Values on each day after starting treatment are compared with the mean levels of two determinations on the control days. ${ }^{*} \mathrm{p}<0.05, * * \mathrm{p}<0.01$.

decreased gradually. Hematocrit fell significantly $(\mathrm{p}<0.01)$ on the 14th day, and total protein fell significantly $(\mathrm{p}<0.01)$ on the 7 th day. Serum sodium increased significantly $(\mathrm{p}<0.05)$ by day 14 , while serum potassium and serum osmolality did not change significantly with treatment. There were no significant alterations in systolic or diastolic blood pressure. Plasma cortisol did not change significantly. Plasma aldosterone decreased slightly, but the change was not significant.

Figure 3 shows the PRA and the plasma ANP levels. PRA decreased significantly $(\mathrm{p}<0.05)$ from the mean level of $5.2 \pm 1.1 \mathrm{ng} / \mathrm{ml} / \mathrm{hr}$ during the control period to $2.8 \pm 1.3 \mathrm{ng} / \mathrm{ml} / \mathrm{hr}$ on day 14 ; it fell to $2.3 \pm 0.5 \mathrm{ng} / \mathrm{ml} / \mathrm{hr}$ by day 21. Plasma levels of ANP averaged $35 \pm 5 \mathrm{pg} / \mathrm{ml}$ during the control period, and were unaffected by insulin $(45 \pm 14 \mathrm{pg} / \mathrm{ml}$ on day $7,36 \pm 5 \mathrm{pg} / \mathrm{ml}$ on day 14 and $36 \pm 3 \mathrm{pg} / \mathrm{ml}$ on day 21 ).

\section{Study 2:}

In the body fluid volume study ( 7 patients), the dose of insulin ranged from 8 to 24 I.U./day (13 2 I.U./day) on day 21 . Table II summarizes the data for fasting plasma glucose levels, hematocrit, PRA, body weight, plasma volume and extracellular fiuid volume in this group. The fasting plasma glucose levels, hematocrit and PRA decreased significantly after starting in- 

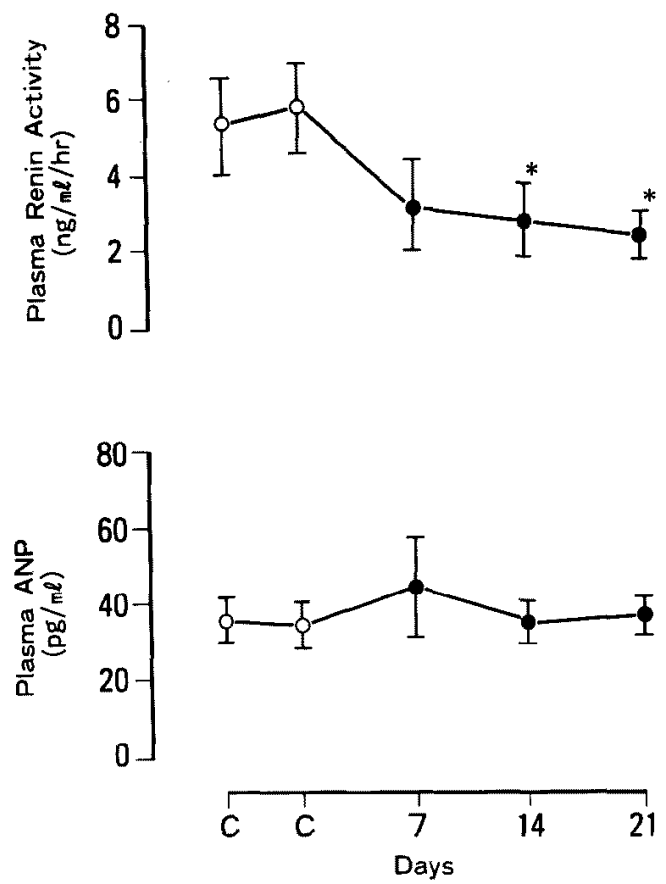

Fig. 3. Changes in plasma renin activity and plasma ANP (mean \pm SEM). Open and closed circles represent data before and after starting insulin, respectively. C indicates the control days before treatment. Data from each day after starting treatment are compared with the mean of two determinations on control days. ${ }^{*} \mathrm{p}<0.05$.

Table II. Hematocrit, Plasma Renin Activity, Body Weight, Plasma Volume and Extracellular Fluid Volume in the Fluid Volume

Study (Study 2, $\mathrm{n}=7$ patients)

\begin{tabular}{l|c|ccc}
\hline & \multirow{2}{*}{$\begin{array}{c}\text { Control } \\
\text { days }\end{array}$} & \multicolumn{3}{|c}{ Days after starting insulin } \\
\cline { 3 - 5 } & & 7 & 14 & 21 \\
\hline Fasting plasma glucose $(\mathrm{mg} / \mathrm{dl})$ & $207 \pm 12$ & $155 \pm 14^{* *}$ & $146 \pm 17^{* *}$ & $131 \pm 14^{* *}$ \\
Hematocrit (\%) & $41.1 \pm 1.8$ & $39.7 \pm 1.4$ & $38.4 \pm 1.4^{*}$ & $37.8 \pm 1.8^{* *}$ \\
Plasma renin activity (ng/ml/hr) & $3.9 \pm 1.6$ & $2.8 \pm 1.0$ & $1.5 \pm 0.3^{*}$ & $0.7 \pm 0.3^{*}$ \\
Body weight (kg) & $47.6 \pm 4.1$ & & & $47.6 \pm 3.8$ \\
Plasma volume (ml/kg) & $40 \pm 3$ & & & $48 \pm 3^{*}$ \\
Extracellular fluid volume (\% body weight) & $28.9 \pm 0.7$ & & & $30.4 \pm 1.1^{*}$
\end{tabular}

Values are mean \pm SEM. Values on each day after starting treatment are compared with the data on the control days. ${ }^{*} \mathrm{p}<0.05$, ** $\mathrm{p}<0.01$.

sulin. Body weight did not change significantly. Plasma volume and extracellular fluid volume increased significantly $(\mathrm{p}<0.05)$ after insulin administration. 


\section{Discussion}

This study has demonstrated that insulin treatment increases both the plasma volume and extracellular volume, with an accompanying fall in hematocrit. PRA decreased significantly in response to the increase in body fluid volume. These results support the reports ${ }^{19,20)}$ that an improvement of glycemic control, by use of insulin or oral hypoglycemics will increase exchangeable body sodium and lower plasma angiotensin II levels in non-ketotic diabetic patients. In these studies, ${ }^{191,20)}$ however, daily sodium intake was not controlled and diabetic patients were treated with either insulin or hypoglycemics.

It has long been known that diabetic patients treated with insulin can develop sodium and fluid retention sufficient to produce edema. Saudek et $\mathrm{al}^{211}$ demonstrated a markcd incrcase in sodium excretion following the abrupt withdrawal of insulin in diabetics; reinstitution of insulin therapy led to a reduction in sodium excretion. DeFronzo et $\mathrm{al}^{22)}$ studied the effects of insulin on the renal handling of sodium in normal subjects with their blood glucose maintained at fasting levels by use of a negative feedback servocontrol. They observed a decrease in sodium excretion, without significant changes in either the blood glucose, the glomerular filtration rate or the filtered load of glucose. These observations suggested a direct effect of insulin on renal sodium handling in diabetics, and agreed with data showing that insulin stimulates active sodium transport across epithelial cells. ${ }^{23)}$

In addition to the sodium-retaining effect of insulin in the kidney, a reduction of the osmotic diuresis and a decrease in urinary glucose will also increase body fluid volume. Serum osmolality did not change significantly, perhaps because the rise in serum sodium compensated for the decrease in plasma glucose. McNair et $\mathrm{al}^{24}$ have reported that increases in blood glucose correlate with decreases in serum sodium in insulin-treated diabetics, and suggested that the development of hyponatremia might be an osmoregulatory response to hypertonicity caused by hyperglycemia. A rise in serum sodium, accompanied by a reduction of urinary sodium, is compatible with sodium retention.

Although a significant decrease in PRA during insulin treatment may be a response to increased body fluid volume, plasma ANP did not change significantly in our patients. In ketotic and severely dehydrated diabetic patients, Tulassay et $\mathbf{a l}^{25}$ ) have reported that plasma ANP increased after salt and fluid replacement and insulin administration. Their study suggested that plasma ANP was depressed in the severely dehydrated state of ketotic diabetes and was subsequently raised by salt and fluid replacement. In their 
study, plasma ANP reached physiological levels on the first day of therapy and did not rise further on the second and third days; however, hyperglycemia was sustained and PRA continued to decrease. In the present study, the pretreatment fasting plasma glucose level was $237 \pm 23 \mathrm{mg} / \mathrm{dl}$, which was comparable with the levels on the second or third days of their study. To the best of our knowledge, this is the first study of the effect of insulin treatment on plasma ANP in non-ketotic diabetic patients. Moreover, throughout our study, the daily sodium intake was kept constant and the only treatment administered was insulin.

During the course of diabetic ketoacidosis and its concomitant severe volume depletion, a marked rise in vasoconstrictor activity has been reported, ${ }^{25), 26)}$ including activation of the renin-angiotensin-aldosterone system, the sympathetic nervous system and an increase in vasopressin levels. In poorlycontrolled, slightly dehydrated non-ketotic diabetic patients, the rise in vasoconstrictor activity may have a role in maintaining cardiovascular homeostasis by counteracting the fall in venous return and maintaining the plasma ANP at a suitable level. It has been reported ${ }^{27)}$ that infusions of angiotensin II, vasopressin and phenylephrine can increase both right atrial pressure and plasma ANP levels.

In the present study, blood pressure declined slightly, despite the apparent sodium retention. Insulin has a vasodilatory action on both resistance and capacitance vessels, independent of the glucose level, ${ }^{28}$ ) and it can modify the cardiovascular system in the absence of hypoglycemia. ${ }^{28)-32}$ ) In uncomplicated diabetes, where the cardiovascular reflexes are normal, insulin increases heart rate with no change in blood pressure. ${ }^{29)}$ However, once autonomic neuropathy or abnormal cardiovascular reflexes have developed, insulin lowers the blood pressure ${ }^{28)}$ and aggravates orthostatic hypotension. ${ }^{30}$ Page et $\mathrm{al}^{30)}$ have reported that this hypotensive effect of insulin occurred whether it was administered intravenously, intramuscularly or subcutaneously. Recently, Yagi et a ${ }^{31)}$ have reported that insulin has an inhibitory effect on the norepinephrine- and angiotensin II-induced constriction of both arteries and veins. Therefore, although insulin administration increases the body fluid volume in diabetic patients, its vasodilatory action may reduce venous return, lower the atrial pressure and prevent a rise in the plasma ANP. In fact, Miles et $\mathrm{al}^{32}$ ) have reported that insulin administration lowers right atrial pressure, in addition to producing a fall in arterial pressure in diabetic patients.

In conclusion, the present study has shown that insulin treatment in diabetes produces both sodium retention and an increase in the plasma and extracellular fluid volumes, accompanied by a fall in PRA. The decrease in 
osmotic diuresis and the sodium-retaining action of insulin may increase body fluid volume. Plasma levels of ANP were unaffected by insulin treatment, suggesting that the vasodilatory effect of insulin may compensate for the increase in body fluid volume.

\section{Acknowledgments}

The authors are grateful to Miss Akemi Yoguchi and Miss Kyoko Onozato for their skillful technical assistance.

\section{REFERENCES}

1. Burden AC, Thurston $\mathrm{H}$ : Plasma renin activity in diabetes mellitus. Clin Sci 56: 255, 1979

2. Gossain VV, Werk EE, Sholiton LJ, Srivastava L, Knowles HG: Plasma renin activity in juvenile diabetes mellitus and effect of diazoxide. Diabetes 24: 833, 1975

3. Christlieb AR: Renin-angiotensin-aldosterone system in diabetes mellitus. Diabetes $\mathbf{2 5}$ (suppl 2): 820, 1976

4. Christlieb AR, Assal J-P, Katsilambros N, Williams GH, Kozak GP, Suzuki T: Plasma renin activity and blood volume in uncontrolled diabetes. Ketoacidosis, a state of secondary aldosteronism. Diabetes 24: 190, 1975

5. Christlieb AR, Kaldany A, D'Elia JA: Plasma renin activity and hypertension in diabetes mellitus. Diabetes 25: 969, 1976

6. Tuck ML, Sambhi MP, Levin L: Hyporeninemic hypoaldosteronism in diabetes mellitus. Studies of the autonomic nervous system's control of renin release. Diabetes 28: 237, 1979

7. Needleman P, Greenwald JE: Atriopeptin: A cardiac hormone intimately involved in fluid, electrolyte, and blood pressure homeostasis. N Engl J Med 314: 828, 1986

8. Nakamura T, Ichikawa S, Sakamaki T, Murata K, Imai T, Anzai T: Atrial natriuretic peptide in patients with cardiac impairment due to open heart surgery. Kitakanto Med J 37: 281, 1987 (in Japanese)

9. Raine AEG, Erne P, Burgisser E, Muller FB, Bolli P, Burkart F, Buhler FR: Atrial natriuretic peptide and atrial pressure in patients with congestive heart failure. $\mathrm{N}$ Engl J Med 315: 533,1986

10. Villarreal D, Freeman RH, Davis JO, Verburg KM, Vari RC: Renal mechanisms for suppression of renin secretion by atrial natriuretic factor. Hypertension 8 (suppl II): II-28, 1986

11. Goodfriend TL, Elliott ME, Stlas SA: Actions of synthetic atrial natriuretic factor on bovine adrenal glomerulosa. Life Sci 35: 1675, 1984

12. Nakamura T, Ichikawa S, Sakamaki T, Fujie M, Yagi A, Kurashina T, Murata K: Plasma levels of atrial natriuretic peptide in patients with borderline and essential hypertension. Tohoku J Exp Med 153: 205, 1988

13. Shenker Y, Sider RS, Ostafin EA, Grckin RJ: Plasma levels of immunoreactive atrial natriuretic factor in healthy subjects and in patients with edema. J Clin Invest 76: 1684, 1985

14. Gregersen MI: A practical method for the determination of blood volume with the dye T1824. A survey of the present basis of the dye-method and its clinical applications. J Lab Clin Med 29: 1266, 1944

15. Kaltreider NL, Meneely GR, Allen JR, Bale WF: Determination of the volume of the extracellular fluid of the body with radioactive sodium. J Exp Med 74: 569, 1941

16. Bowler RG: The determination of thiocyanate in blood serum. Biochem J 38: 385, 1944

17. Ichikawa S, Tajima Y, Sakamaki T, Matsuo H, Kogure M, Hirano Y, Yagi S, Murata K: 
Effect of spironolactone on fluid volumes and adrenal steroids in primary aldosteronism. Jpn Circ J 48: 1184,1984

18. Nakamura T, Ichikawa S, Sakamaki T, Sato K, Kogure M, Tajima Y, Kato T, Murata K: Role of atrial natriuretic peptide in mineralocorticoid cscape phenomenon in patients with primary aldosteronism. Proc Soc Exp Biol Med 185: 448, 1987

19. O'Hare JA, Ferriss JB, Twomey BM, Gonggrijp H, O'Sullivan DJ: Changes in blood pressure, body fluids, circulating angiotensin II and aldosterone, with improved diabetic control. Clin Sci 63: 415s, 1982

20. Sullivan PA, Gonggrijp H, Crowley MJ, Ferriss JB, O'Sullivan DJ: Plasma angiotensin II and the control of diabetes mellitus. Clin Endocrinol 13:387, 1980

21. Saudek CD, Boulter PR, Knopp RI, Arky RA: Sodium retention accompanying insulin treatment of diabetes mellitus. Diabetes 23: 240, 1974

22. DeFronzo RA, Cooke GR, Anders R, Faloona GR, Davis PJ: The effect of insulin on renal handling of sodium, potassium, calcium, and phosphate in man. J Clin Invest 55: 845, 1975

23. Cox M, Singer I: Insulin-mediated $\mathrm{Na}$ transport in the toad urinary bladder. Am J Physiol 232: F270, 1977

24. McNair P, Madsbad S, Christiansen C, Christensen MS, Transbøl I: Hyponatremia and hyperkalemia in relation to hyperglycemia in insulin-treated diabetic out-patients. Clin Chim Acta 120: 243, 1982

25. Tulassay T, Rascher W, Körner A, Miltényi M: Atrial natriuretic peptide and other vasoactive hormones during treatment of severe diabetic ketoacidosis in children. J Pediatr 111: 329,1987

26. Zerbe RL, Vinicor F, Robertson GL: Plasma vasopressin in uncontrolled diabetes mellitus. Diabetes 28: 503,1979

27. Katsube N, Schwartz D, Needleman P: Release of atriopeptin in the rat by vasoconstrictors or water immersion correlates with changes in right atrial pressure. Biochem Biophys Res Commun 133: 937, 1985

28. Tanaka S, Yamamoto M, Yagi S, Noto Y, Ikeda T, Hattori N: Peripheral circulatory effects of insulin in diabetes. Angiology 36: 110, 1985

29. Page MMcB, Smith RBW, Watkins PJ : Cardiovascular effects of insulin. Br Med J 1: 430 , 1976

30. Page MMcB, Watkins PJ: Provocation of postural hypotension by insulin in diabetic autonomic neuropathy. Diabetes 25: 90,1976

31. Yagi S, Takata S, Kiyokawa H, Yamamoto M, Noto Y, Ikeda T, Hattori N: Effects of insulin on vasoconstrictive responses to norepinephrine and angiotensin II in rabbit femoral artery and vein. Diabetes 37: 1064, 1988

32. Miles DW, Hayter CJ: The effect of intravenous insulin on the circulatory responses to tilting in normal and diabetic subjects with special reference to baroceptor reflex block and atypical hypoglycemic reactions. Clin Sci 34: 419, 1968 